\title{
CORPO E CONSTRUÇÃO DO CONHECIMENTO: UMA REFLEXÃO PARA A EDUCAÇĀO INFANTIL
}

\author{
Marina Célia Moraes DIAS*
}

É com prazer que participo deste seminário "Educação Física Escolar: Conhecimento e Especificidade", para o qual trago algumas reflexð̃es sobre a educação da criança pequena, de zero a seis anos, período que antecede a educação formal.

O que seria um processo de "escolarização" neste momento da vida? Quais seriam os eixos centrais do currículo de educação infantil? Que papel caberia à Educação Física no projeto educacional?

Gostaria de centrar minha discussão em torno de uma questão que considero crucial neste período da vida da criança que tem sido pouco enfatizada nos debates sobre educaçáo infantil e que acredito possa trazer uma nova luz na construção de projetos pedagógicos para a criança pequena. Trata-se do processo de simbolização do corpo, primeiro instrumento de pensamento da criança no seu diálogo com o mundo, processo no qual a Educação Física, compreendida no seu sentido mais profundo, tem um papel fundamental. Corpo que se constrói não apenas fisicamente, mas que desde a concepção é fruto do encontro de dois corpos em movimento de estabelecimento de vínculo, corpo que é físico, mas acima de tudo simbólico-sensual.

Como diz Wallon, o ser humano é geneticamente social e a própria natureza humana se constitui num processo de interação inter-pessoal e inter-cultural, cabendo ao corpo papel principal (Dantas, 1992). Assim é que a psicogênese da motricidade se confunde com a psicogênese da pessoa. $O$ ato mental se desenvolve a partir do ato motor, o qual se expressa num primeiro momento muito mais na sua funçăo cinética - o movimento físico propriamente dito - como mecanismo de ação e expressão da criança no mundo. $O$ auge deste pensamento via movimento se observa no período sensório-motor e se prolonga durante toda a pequena infância, justificando a afirmação de que a criança pensa na açăo. Paulatinamente, no decorrer do desenvolvimento, o ato motor vai cedendo lugar ao movimento tônico, concentrado na postura, pois com o crescente domínio dos signos culturais, a motricidade em sua dimensão cinética tende a se reduzir e se virtualizar em ato mental. Mesmo assim, a musculatura permanece envolvida em atividade tônica, que pode ser intensa; pensa-se com o corpo em sentido duplo - com o cérebro e com os músculos (Dantas, 1992).

Wallon (1968) ainda nos mostra como a motricidade humana comeca pela atuaça sobre o meio social para depois poder modificar o meio físico. É através da função tônica do movimento, principalmente no seu aspecto de motricidade expressiva da mímica, inteiramente ineficaz do ponto de vista instrumental (não faz transformações diretas ao ambiente físico, mas é extremamente relevante sobre o meio social) que o individuo humano atua sobre o outro. É isto que lhe permite sobreviver durante o prolongado período de dependência. A inclusão da etapa "impulsivo-expressivo-emocional" (zero a um ano) antecedendo a "sensório-motora" (um a dois anos), proposta por Wallon, amplia e esclarece a compreensão do caminho do "ato ao pensamento", mostrando como desde o início o corpo não é neutro mas se nutre das relaçóes pessoais e culturais, constituindo-se no principal instrumento da criança no seu diálogo com o mundo social, possibilitando-lhe apropriar-se da cultura e construir o pensamento.

$O$ processo de erotização do corpo, alimentado pelas relações afetivas interpessoais, iniciadas no primeiro ano de vida e enriquecido pelas novas possibilidades de ação no mundo que o desenvolvimento psicomotor traz (possibilidade de andar, correr, ajustar movimentos e percepcão ao conhecimento do mundo), permitem a criança a construção de uma postura ativa diante do mundo, abrindo um caminho para

\footnotetext{
"Faculdade de Educação, Universidade de São Paulo.
} 
sua auto-afirmação enquanto sujeito. Num primeiro momento, o sujeito anda comandado pelos cinco sentidos e pelo próprio movimento, pois a motricidade e a percepção não estão de todas diferenciadas (Vygotsky, 1984; escada é para subir e descer, areia é para encher baldes e esvaziá-los, etc). É o movimento que comanda o pensamento. Porém, a criança rapidamente se tornará sujeito das suas próprias açóes através da capacidade de simbolização, tendo o corpo como grande mediador. Podemos dizer, utilizando uma imagem sugerida por Merleau-Ponty (1975) (no seu belíssimo texto sobre Cézanne, buscando compreender a natureza do trabalho do pintor dizendo que este "empresta seu corpo ao mundo e o transforma em pintura") que a criança empresta seu corpo ao mundo e o transforma em pensamento.

É através da imaginação em ação, a imaginação que se expressa diretamente pelo corpo na forma de jogo simbólico, que a criança a partir de meados do segundo ano de vida conquista a dimensăo simbólica do pensamento que lhe abrirá as portas para o mundo dos homens propriamente dito, ou seja, o mundo da cultura. Wallon (1968) nos mostra como a criança vai aos poucos projetando seu pensamento através de ideomovimentos que vão lhe possibilitando ultrapassar os limites sensório-motores do comportamento. No entanto é Vygotsky (1984) que nos ilumina profundamente este momento precioso da passagem para a inteligência simbólica, ressaltando com toda clareza a função do corpo, da imaginação em ação (brinquedo) como primeira possibilidade de açåo da criança numa etapa cognitiva que lhe permite ultrapassar a dimensão percepção motora do comportamento. "A imaginação é um processo psicológico novo para a criança; representa uma forma especificamente humana da atividade consciente que não está presente na consciência das crianças muito pequenas e está ausente nos animais. Ela surge em forma de jogo, que é a imaginação em ação. Como todas as funçôes da consciência ela surge originalmente da ação. $O$ velho adágio de que o brincar da criança é a imaginação em ação deve ser invertido, podemos dizer que a imaginação nos adolescentes e nos adultos é o brinquedo sem açăo" (Vygotsky, 1984).

Para Piaget (1975), também a representação em atos, através do jogo simbólico, a primeira possibilidade de pensamento propriamente dito, marcando a passagem de uma inteligência sensório-motora para uma inteligência pré-operatória (material e intuitiva) mediada por símbolos subjetivos, caminho para a construção da inteligência operatória, mediada por signos históricos arbitrários.

Obrigada a adaptar-se sem cessar a um mundo social dos mais velhos, cujos interesses e cujas regras lhe permancecem exteriores, e ao mundo fisico, que ela ainda mal compreende, a criança para seu equilíbrio afetivo e intelectual precisa dispor de um setor de atividade cuja motivação não seja a adaptação ao real senão pelo contrário a assimilação do real ao eu sem coaçóes nem sansð̃es: tal é o jogo, que transforma o real por assimilação mais ou menos pura às necessidades do eu, ao passo que a imitação é acomodação mais ou menos pura aos modelos exteriores e a inteligência é o equilíbrio entre assimilação e acomodação (Piaget, 1975).

Assim, na criança, a imaginação criadora surge em forma de jogo, instrumento primeiro de pensamento no enfrentamento da realidade. Jogo sensório-motor que se transforma em jogo simbólico, ampliando as possibilidades de ação e compreensão do mundo. $O$ conhecimento deixa de estar preso ao aqui e agora, aos limites da mão, da boca e do olho e o mundo inteiro pode estar presente dentro do pensamento, uma vez que é possível "imaginá-lo", representá-lo através dos símbolos.

\section{Mentiras}

Lili vive no mundo do Faz-de-conta... Faz de conta que isto é um aviåo. Zzzzuuu... Depois aterrisou em piquê e virou trem. Tuc tuc tuc tuc... Entrou pelo túnel, chispando. Mas debaixo da mesa havia bandidos. Pum! Pum! Pum! O trem descarrilou. E o mocinho? Meu Deus! onde é que está o mocinho! No auge da confusão, levaram Lili para a cama, à força. E o trem ficou tristemente derribado no chão, fazendo de conta que era mesmo uma lata de sardinha. (Quintana, 1983).

Esta inteligência simbólico-corporal se amplia com a utilização de objetos transformados em brinquedos, e também com o uso de instrumentos plásticos e sonoros, dando origem a diferentes linguagens expressivas - corporal, plástica e musical - articuladas à aquisiçăo da fala. Abre-se então caminhos para a construção da linguagem escrita, já um sistema de representação mais abstrato, pois de segunda ordem (representação da representaçăo, representação da fala). 
Neste processo, a criança vai aos poucos se constituindo como sujeito cultural, apropriando-se do conhecimento histórico-social acumulado (áreas do conhecimento), ao mesmo tempo que constrói seus instrumentos de pensamento e de ação no mundo.

A construção da identidade pessoal é pois ao mesmo tempo histórica e cultural e se constitui através da interação entre os homens num processo de espelhamento e diferenciação dentro de um contexto de significaçoses sociais, onde o corpo enquanto suporte físico-afetivo-cultural tem papel fundamental.

A partir destas reflexões, podemos concluir que a escolarização no seu sentido mais amplo pode, em qualquer nível de ensino, ser traduzida como a educação do corpo, instrumento sensível de compreensấo do mundo, de construção de vínculo com outros corpos sensíveis e simbólicos e com o corpo político, histórico e cultural que possibilitará aos homens a construção da pertinência do grupo, da identidade pessoal e coletiva e da cidadania. E que esta educação tem seu início nos primeiros anos de vida, cabendo pois à Educaçáo Física trazer este enfoque ao currículo pré-escolar.

\section{REFERÊNCIAS BIBLIOGRÁFICAS}

DANTAS, H. Do ato motor ao ato mental: a gênese da inteligência segundo Wallon. In: La TAllLE, Y.; OLIVEIRA, M.K.; DANTAS, H. Teorias psico-genéticas em discussão. Såo Paulo, Summus, 1992.

MERLEAU-PONTY, M. O olho e o espírito. In: TEXTOS estéticos. Såo Paulo, Abril Cultural, 1975. (Coleção "Os Pensadores")

QUINTANA, M. Lili inventa o mundo. 12.ed. Porto Alegre, Mercado Aberto, 1993.

PIAGET, J. A formaçĩo do símbolo na criança. São Paulo, Zahar, 1975.

VYGOTSKY, L.S. A formação social da mente. São Paulo, Martins Fontes, 1984.

WALLON, H. A evolução psicológica da criança. Lisboa, Persona/Martins Fontes, 1968. 